\title{
USULAN BIAYA PREVENTIVE MAINTENANCE DENGAN MENGGUNAKAN METODE MODULARITY DESIGN PADA MESIN RIPPLE MILL DI PT. INCASI RAYA POM
}

\author{
Henny Yulius ${ }^{1)}$, Fredy Tri Susanto ${ }^{2)}$ \\ ${ }^{1}$ Jurusan Teknik Industri, Sekolah Tinggi Teknologi Industri Padang \\ email: henny.yulius0101@gmail.com
}

\begin{abstract}
Abstrak
Abstrak: PT. Incasi Raya POM, merupakan perusahaan yang bergerak di bidang industri, yang kegiatan utamanya adalah pengolahan kelapa sawit. Untuk mempertahankan kualitas dan produktivitas, faktor penting yang harus diperhatikan adalah masalah perawatan (maintenance) mesin dan fasilitas produksi serta biaya perawatan. Sehingga pihak yang mendapatkan tugas menangani perawatan tersebut perlu menerapkan kebijakan untuk sistem perawatan yang paling baik bagi perusahaan. Penelitian ini dilakukan untuk membahas masalah tentang meminimasi biaya perawatan mesin press yang ada pada PT. Incasi Raya POM. Metode yang digunakan untuk membandingkan biaya perawatan mesin ripple mill adalah modularity design yang didisribusikan pada periode tahun 2019. Dengan total kerusakan pada setiap komponen sebanyak 39 kerusakan. Total biaya perbaikan mesin paa cost of failure (CF) didapatkan hasil dengan total Rp. 34.880.198, pada cost of Preventive (CP) didapat hasil dengan total Rp. 84.757.652, dan pada cost of preventive modularity (CPM) didapatkan hasil dengan total Rp. 20.376 .324 pertahun. Dari total biaya tersebut PT. Incasi Raya POM bisa mengetahui berapa total biaya perawatan mesin ripple mill ini untuk tahun kedepannya, yang memungkinkan perusahaan bisa menghemat anggaran dalam proses perawatan mesin ripple mill pada bagian proses produksi kelapa sawit.
\end{abstract}

Kata kunci: Modularity Design, Cost Of Preventive, Cos Of Failure.

Abstract: PT. Incasi Raya POM, is a company engaged in the field of industry, which is engaged in palm oil processing. To maintain quality and productivity, important factors that must be considered are issues of maintenance (maintenance) of machines and production facilities and maintenance costs. Related to the party who gets the maintenance assignment, the policy needed for the best treatment system for the company. This research was conducted to discuss the problem of minimizing the cost of maintenance of existing press machines at PT. POM Raya Incasi. The method used to compare the maintenance costs of ripple mill machines is the modularity design that was distributed in the period 2019. With a total damage of each component as many as 39 damage. The total cost of repairing the machine at the cost of failure (CF) results in a total of Rp. 34,880,198, the cost of Preventive (CP) yields a total of Rp. 84,757,652, and at the cost of preventive modularity (CPM) get results with a total of Rp. 20,376,324 per year. Of the total costs, PT. Incasi Raya POM can find out how much the total maintenance cost for this ripple machine in the future, which allows the company to save budget in the process of ripple machine maintenance in the palm oil production process.

Keywords: Modularity Design, Cost Of Preventive, Cos Of Failure.

\section{PENDAHULUAN}

Ketatnya persaingan dalam dunia bisnis mengharuskan bagi setiap perusahaan untuk bekerja ekstra keras untuk dapat mempertahankan eksistensinya dalam bidang usahanya.
Sebagai usaha untuk mengantisipasi ketatnya persaingan ini PT. Incasi Raya POM ingin terus memberikan yang terbaik bagi konsumennya dengan memberikan sesuai apa yang diinginkan oleh konsumennya baik secara kuantitas 
maupun kualitas. PT. Incasi Raya POM harus dapat menjaga konsistensinya dalam kelangsungan proses produksinya untuk dapat memenuhi permintaan tersebut.

Kerusakan - kerusakan yang terjadi pada mesin ada yang dapat terdeteksi secara langsung dan adapula yang tidak dapat terdeteksi. Kerusakan yang terdeteksi akan memberikan gangguan terhadap kelangsungan proses produksi.

Mesin ripple mill adalah salah satu mesin yang wajib ada di sebuah stasiun kernel pengolahan kelapa sawit. Kegunaan cangkang sawit yang sangat besar membuat pengolahan sawit tidak menimbulkan limbah yang cukup banyak. Semua bagian sawit yang tidak mengalami pengolahan dapat dimanfaatkan terutama cangkang nut sawit ini. Adapun tujuan diadakannya penelitian ini yaitu untuk membandingkan biaya maintenance antara metode awal dari perusahaan dengan usulan biaya perawatan preventive maintenance setelah menggunkan metode modularity.

(Ekawati and Mustofa, 2016) Perawatan atau maintenance adalah aktivitas agar suatu komponen atau sistem yang rusak dapat dikembalikan atau diperbaiki dalam suatu kondisi tertentu pada periode tertentu. Menurut pengertian tersebut dapat disimpulkan bahwa maintenance merupakan suatu tindakan untuk menjaga atau memelihara fasilitas maupun memperbaiki fasilitas yang rusak sehingga saat akan digunakan fasilitas tersebut dapat bekerja sesuai fungsinya dan manajemen perawatan industri adalah upaya pengaturan aktivitas untuk menjaga kontinuitas produksi, sehingga dapat menghasilkan produk yang berkualitas dan memiliki daya saing melalui pemeliharaan fasilitas.

Perawatan atau lebih dikenal dengan kata maintenance dapat didefenisikan sebagai suatu aktivitas yang diperlukan untuk menjaga atau mempertahankan kualitas pemeliharaan suatu fasilitas agar fasilitas tersebut tetap dapat berfungsi dengan baik dalam kondisi siap pakai.
Sedangkan fasilitas yang dimaksudkan di sini sudah barang tentu bukannya hanya fasilitas seperti mesin-mesin produksi saja yang memerlukan perawatan tetapi juga fasilitas lain seperti generator, diesel, dan utilitas pabrik lainnya, dan bahkan peralatan kantor seperti komputer, mesin tik ataupun peralatan angkut seperti crane, forklif, dan lain-lain Sudradjat (2011).

Dalam menyusun produk yang modular digunakan pembandingan antara component tree dan process graph dari sebuah produk dan memastikan pada setiap detail level, atribut produk bersifat independence dan atribut lainnya selama memungkinkan untuk setiap detail level dari life cycle process. Untuk meningkatkan independence dan similarity, sebuah produk didesain dengan segi modularity.

\section{METODE PENELITIAN}

Data yang dikumpulkan untuk mendukung penelitian ini meliputi data spesifikasi komponen, data kerusakan komponen dapat dilihat pada lampiran, data harga komponen, data waktu penggantian pencegahan, data waktu penggantian kerusakan, data biaya pencegahan dan data biaya kerusakan serta gaji karyawan perbulan pada tahun 2019.

Mean Time To Failure (MTTF) merupakan nilai rata rata waktu kegagalan dari sebuah sistem (komponen). MTTF dapat dirumuskan sebagai berikut :

$$
\begin{array}{cl}
\text { MTTF }= & \alpha \mathrm{r}(1+1 / \beta) \\
\text { Dimana : } & \\
\begin{array}{cl}
\mathrm{a} & =\text { Parameter skala } \\
\beta & =\text { Parameter bentuk } \\
\mathrm{r} & =\text { Fungsi gamma }
\end{array}
\end{array}
$$

Probabilitas kerusakan mencerminkan bahwa kerusakan akan terjadi walaupun sudah dilakukan pemeliharaan pencegahan. Banyaknya kerusakan K yang diharapkan terjadi secara kumulatif dalam B bulan dengan persamaan sebagai berikut (Sudradjat, 2011): 


$$
\begin{aligned}
& \mathrm{Kn} \\
& \sum_{1}^{n} P n+K_{n-1} P_{1}+K_{n-2} P_{2}+\cdots+K_{1} P_{n-1} \\
& \text { Dimana : } \\
& \mathrm{N}=\text { Banyaknya satuan } \\
& \mathrm{P}=\text { Probabilitas rusak selama bulan } \\
& \quad \text { tertentu setelah pemeliharaan } \\
& \mathrm{n}=\text { Periode pemeliharaan. }
\end{aligned}
$$

Fungsi dan parameter keandalan untuk masing-masing distribusi berbeda antara satu dengan yang lainnya. Di bawah ini akan diberikan fungsi keandalan untuk distribusi normal, lognormal, Weibull, dan eksponential.

Perhitungan parameter distribusi weibull yang terpilih untuk masingmasing komponen dengan persamaan sebagai berikut (Mustofa, 2016) :

$$
\begin{gathered}
F t(i)=\frac{i-0,3}{n+0,4} \\
\qquad i=L N\left[L N \frac{1}{1-F\left(t_{i}\right)}\right. \\
Y i=L N(T i) \\
\text { Ratio }=X i \times Y i \\
b=\frac{n \sum_{i=1}^{n} X i \cdot Y i-\sum_{i=1}^{n} X i \cdot \sum_{i=1}^{n} Y i}{n \sum_{i=1}^{n} X i^{2}-\left(\sum_{i=1}^{n} X\right)^{2}} \\
a=\frac{\sum_{i=1}^{n} Y i}{n}-b \frac{\sum_{i=1}^{n} X i}{n} \\
\quad \beta=\frac{1}{b}
\end{gathered}
$$

Perhitungan parameter distribusi lognormal yang terpilih untukmasingmasing komponen dengan persamaan sebagai berikut (Mustofa 2016) :

$$
\begin{array}{r}
X i=L N(T i) \\
\mu=\frac{\sum_{i=1}^{n} L N(T i)}{n} \\
\text { Variabel }=(X i-\mu)^{2} \\
\sigma=\sqrt{\frac{\sum_{i=1}^{n}(L N(T i)-\mu)^{2}}{n}}
\end{array}
$$

Perhitungan untuk Cost Of Preventive (Cp) untuk masing-masing komponen kritis dengan persamaan sebagai berikut (Mustofa, 2016) :
Biaya $\mathrm{Cp}$ meliputi :

Biaya Operator Menganggur $=$ Waktu Pencegahan Penggantian x Biaya Operator Menganggur

$\mathrm{Cp}=$ Biaya Pembelian Komponen /Kebutuhan + Biaya Teknisi + Biaya Pemasangan + Biaya Operator Menganggur.

Perhitungan untuk Cost Of Failure (Cf) untuk masing-masing komponen dengan persamaan sebagai berikut (Mustofa, 2016):

Biaya Cf meliputi:

Biaya Operator Menganggur $=$ Waktu Pencegahan Penggantian x Biaya Operator

$\mathrm{Cf}=$ Biaya Pembelian Komponen/Kebutuhan + Biaya Teknisi + Biaya Pemasangan + Biaya Operator Menganggur + Biaya Komponen yang Ikut Diganti.

\section{Bentuk Kebijakan Perawatan}

Bentuk kebijakan perawatan terdiri dari beberapa bagian (Sudradjat, 2011) yaitu dapat dijabarkan sebagai berikut :

Perawatan kerusakan dapat diartikan sebagai kebijakan perawatan dengan cara mesin/peralatan dioperasikan hingga rusak, kemudian baru diperbaiki atau diganti. Kebijakan ini merupakan strategi yang sangat kasar dan kurang baik karena dapat menimbulkan biaya tinggi, kehilangan kesempatan untuk mengambil keuntungan bagi perusahaan karena diakibatkan terhentinya mesin, keselamatan kerja tidak terjamin, kondisi mesin tidak diketahui, dan tidak ada perencanaan waktu, tenaga kerja maupun biaya yang baik (Sudradjat, 2012).

Perawatan pencegahan adalah perawatan yang dilakukan sebelum terjadi kerusakan mesin. Kebijakan ini cukup baik untuk mencegah berhentinya mesin yang tidak direncanakan. Literatur pertama mengenai perawatan pencegahan ini di terbitkan pada tahun1925, tentang sistem pemeriksaan secara teratur terhadap kendaraan yang dimulai pada tahun 1930 di pabrik baja USA. Diperkenalkan di 
Jepang pada tahun 1951 dari ESSO oleh Toa full co.

\section{Model Perhitungan Total Ekspektasi Biaya Penggantian}

Ekawati and Mustofa (2016), tujuan menentukan selang waktu penggantian komponen yang optimal adalah untuk meminimumkan total ekspektasi biaya penggantian per satuan waktu. Persamaan berikut merupakan total ekspektasi biaya penggantian komponen per satuan waktu. Rumus untuk mengetahui ekspektasi total biaya perawatan per satuan waktu dapat dilihat pada persamaan berikut :

(Pers 2.7)

$$
\mathrm{C}\left(\mathrm{t} \_\mathrm{p}\right)=\left(\mathrm{Cp} \times \mathrm{R}\left(\mathrm{t} \_\mathrm{p}\right)+\left(\mathrm{Cf} \times \mathrm{F}\left(\mathrm{t} \_\mathrm{p}\right)\right)\right) / \mathrm{tp}
$$

Dimana :

$\mathrm{C}(\mathrm{tp})=$ Ekspektasi total biaya penggantian per satuan waktu (tp)

$\mathrm{Cf}=$ Ongkos penggantian kerusakan untuk melakukan penggantian pencegahan

$\mathrm{Cp}=$ Ongkos penggantian pencegahan untuk melakukan penggantian pencegahan

$\mathrm{f}(\mathrm{tp})=$ Probability dencity function (tp)

$\mathrm{Tp}=$ Waktu yang dibutuhkan untuk melakukan penggantian pencegahan

$\mathrm{R}(\mathrm{tp})=$ Fungsi keandalan peralatan atau mesin pada waktu tp

\section{Kebijakan Repair Maintenance Dan Preventive Maintenance}

Menurut Pujotomo dan Kartha (2012) dan Zulaikah \& Fajriah (2013), dalam memilih antara kebijakan repair maintenance dan preventive maintenance, dapat dilakukan dengan menggunakan metode yang telah ada untuk mencari biaya total perawatan (total maintenance cost) yang paling rendah. Metode repair policy (kebijakan perbaikan) dapat dicari dengan menggunakan rumus berikut (Smith dan Mobley, 2016) :

$\mathrm{TMC}($ repairpolicy $)=\mathrm{TCr}=$ Expected cost of repair

$$
\begin{aligned}
& \mathrm{TCr}=\mathrm{B} . \mathrm{Cr} \\
& \mathrm{B}=\mathrm{N} / \mathrm{Tb}
\end{aligned}
$$

$\mathrm{Tb}=\sum \mathrm{i}$ pi . Ti (Pers 2.8)

Di mana: bulan.

$\mathrm{TCr}=$ expected cost of repair per

$\mathrm{B}=$ jumlah rata-rata breakdown/ bulan untuk $\mathrm{N}$ mesin.

$\mathrm{Cr}=$ biaya perbaikan.

$\mathrm{Tb}=$ rata-rata runtime per mesin sebelum rusak.

$\mathrm{N}=$ jumlah mesin

Sebelum masuk ke data kerusakan mesin terlebih dahulu kita memerlukan data kariawan, mulai dari jumlah karyawan pada perbaikan, biaya karyawan.

Tabel 1. Data Komponen Penyusun Kerusakan Mesin

\begin{tabular}{|l|c|c|c|}
\hline \multicolumn{4}{|c|}{ Data Frekuensi Kerusakan Mesin Ripple Mill Pada Tahun 2019 } \\
\hline Komponen & Kebutuhan & $\begin{array}{c}\text { Harga/Komponen } \\
\text { (Rp) }\end{array}$ & $\begin{array}{c}\text { Harga/Kebutuhan Komponen } \\
\text { (Rp) }\end{array}$ \\
\hline Rotor & 2 & 350,000 & 700,000 \\
\hline As Rotor & 1 & $1,200,000$ & $1,200,000$ \\
\hline Piringan & 2 & 450,000 & 900,000 \\
\hline Bar Rotor & 1 & $2,600,000$ & $2,600,000$ \\
\hline Spacer Ring & 4 & 80,000 & 320,000 \\
\hline Ripple Plate & 2 & 250,000 & 500,000 \\
\hline Bantalan & 2 & 150,000 & 300,000 \\
\hline Ripple Side & 5 & 80,000 & 400,000 \\
\hline Motor Listrik & 1 & $4,500,000$ & $4,500,000$ \\
\hline V- Belt & 2 & 120,000 & 240,000 \\
\hline
\end{tabular}

Data yang diolah dalam penelitian ini berupa data data spesifikasi komponen, data kerusakan komponen, data harga komponen, data waktu penggantian pencegahan, data waktu penggantian kerusakan, data biaya pencegahan dan data biaya kerusakan pada tahun 2019 .

Pengumpulan data dilakukan secara langsung di lapangan dengan meminta operator untuk mengisi kuesioner. Kuesioner diisi oleh 10 orang responden dimana respondennya merupakan operator yang bekerja pada bagian tersebut. Pengumpulan data ini didampingi langsung oleh penelitian. Data pada kuesioner yang dikumpulkan meliputi data umum responden, rating indikator beban kerja psikologis operator, dan perbandingan berpasangan indikator beban kerja psikologis yang menyebabkan 
timbulnya beban kerja psikologis operator tersebut.

\section{HASIL DAN PEMBAHASAN}

Data yang diolah dalam penelitian ini berupa data-data spesifikasi komponen, data kerusakan komponen, data harga komponen, data waktu penggantian pencegahan, data waktu penggantian kerusakan, data biaya pencegahan dan data biaya kerusakan pada tahun 2019, dapat dilihat sebagai berikut :

\section{Perhitungan Penentuan Komponen Kritis}

Perhitungan pemilihan komponen kritis pada mesin ripple mill dapat dilihat pada tabel berikut :

Tabel 2. Perhitungan Penentuan Komponen Kritis

\begin{tabular}{|c|c|c|c|c|c|}
\hline Komponen & $\begin{array}{c}\text { Frekuensi } \\
\text { Kerusakan } \\
\text { /Tahun }\end{array}$ & $\begin{array}{c}\text { Harga/Kebutuhan } \\
\text { (Rp) }\end{array}$ & $\begin{array}{c}\text { Biaya } \\
\text { Pergantian } \\
\text { (Rp) }\end{array}$ & $\begin{array}{c}\text { Persentase } \\
(\%)\end{array}$ & $\begin{array}{c}\text { Persentase } \\
\text { Kumulatif } \\
(\%)\end{array}$ \\
\hline Rotor & 3 & 350.000 & 1.050 .000 & 0,05 & 0,05 \\
\hline As Rotor & 4 & 1.200 .000 & 4.800 .000 & 0,24 & 0,29 \\
\hline Piringan & 2 & 450.000 & 900.000 & 0,04 & 0,33 \\
\hline Bar Rotor & 2 & 2.600 .000 & 5.200 .000 & 0,26 & 0,59 \\
\hline Spacer Ring & 5 & 80.000 & 400.000 & 0,02 & 0,61 \\
\hline Ripple Plate & 6 & 250.000 & 1.500 .000 & 0,07 & 0,69 \\
\hline Bantalan & 4 & 150.000 & 600.000 & 0,03 & 0,72 \\
\hline Ripple Side & 5 & 80.000 & 400.000 & 0,02 & 0,74 \\
\hline Motor Listrik & 1 & 4.500 .000 & 4.500 .000 & 0,22 & 0,96 \\
\hline V-Belt & 7 & 120.000 & 840.000 & 0,04 & 1,00 \\
\hline \multicolumn{3}{|c|}{ Total } & $20,190,000$ & 1 & \\
\hline
\end{tabular}

\section{Perhitungan Uji Index Of Fit (Arena)}

Pola distribusi yang terpilih adalah pola dengan nilai index of fit terbesar, bentuk pola grafik dari uji index of fit dapat diliha pada lampiran, rekapitulasi pola distribusi kerusakan yang terpilih dapat dilihat pada tabel berikut :

\section{Tabel 3. Perhitungan Uji Index Of Fit (Arena)}

\begin{tabular}{|c|c|c|c|c|c|c|c|c|c|}
\hline \multirow{2}{*}{ Ilkin } & \multirow{2}{*}{$\begin{array}{c}\text { Komponen } \\
\text { Kritis }\end{array}$} & \multicolumn{8}{|c|}{ 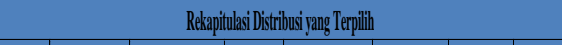 } \\
\hline & & Nomal & Logrumanal & Elkponerenial & Tredoull & Teprilith & Parameter & Stahl (a) & $\operatorname{Beta}($ if \\
\hline & Spacer Ring & 0,0028 & 0,036 & 0,04 & 0,02026 & Elsponenesial & 2 & 0,417 & 0,15 \\
\hline & Riplel Plate & 0,00104 & 0,0986 & 0,089 & 0,0048 & Elsponenesial & 2 & 0.5 & 0,522 \\
\hline & Riples Side & 0,0028 & 0,0236 & 0,44 & 0,0026 & Exsponensial & 2 & 0,417 & 0,15 \\
\hline & V-Bett & 0,0028 & 0,073 & 0,153 & 0,0667 & Elsponenesial & l & 0.583 & 0,515 \\
\hline
\end{tabular}

\section{Perhitungan Waktu Rata-rata Penggantian Komponen}

Perhitungan waktu rata-rata penggantian komponen pada masing-masing komponen kritis dapat dilihat pada tabel berikut :
Tabel 4. Perhitungan Waktu Rata-rata Penggantian Komponen

\begin{tabular}{|c|l|c|c|c|c|c|}
\hline \multirow{2}{*}{ Mesin } & $\begin{array}{c}\text { Komponen } \\
\text { Kritis }\end{array}$ & $\begin{array}{c}\text { Frekuensi } \\
\text { Kerusakan/Tahun }\end{array}$ & $\begin{array}{c}\text { Waktu Rata-rata } \\
\text { Distribusi }\end{array}$ & $\begin{array}{c}\text { Rata- } \\
\text { rata } \\
\text { (Jam) }\end{array}$ & $\begin{array}{c}\text { Rata- } \\
\text { rata } \\
\text { (Menit) }\end{array}$ & $\begin{array}{c}\text { Rata- } \\
\text { rata } \\
\text { (Detik) }\end{array}$ \\
\hline \multirow{4}{*}{$\begin{array}{c}\text { Ripple } \\
\text { Mill }\end{array}$} & Spacer Ring & 5 & 12 & 0.040 & 2.400 & 144.00 \\
\cline { 2 - 7 } & Ripple Plate & 6 & 12 & 0.033 & 2.000 & 120.00 \\
\cline { 2 - 8 } & Ripple Side & 5 & 12 & 0.040 & 2.400 & 144.00 \\
\cline { 2 - 8 } & V-Belt & 7 & 12 & 0.029 & 1.714 & 102.86 \\
\hline
\end{tabular}

Waktu Rata - rata $=\frac{\text { Waktu Rata }- \text { rata Distribusi }}{\text { Frekueni } \text { Kerusakan } / \text { Tahun }}$ $=\frac{12}{5}=2,400$ Menit $=0,040 \mathrm{Jam}=144,00$ Detik

\section{Perhitungan Biaya Tenaga Kerja Perawatan Mesin \\ Perhitungan upah tenaga kerja} berdasarkan perawatan mesin yang ada di perusahaan dapat dilihat sebagai berikut :

Tabel 5. Perhitungan Biaya Tenaga Kerja Perawatan Mesin

\begin{tabular}{|c|c|c|c|c|c|c|}
$\begin{array}{c}\text { Jam } \\
\text { Geja/ } \\
\text { Iari }\end{array}$ & $\begin{array}{c}\text { Hari } \\
\text { Kerja/Minggu }\end{array}$ & $\begin{array}{c}\text { Jam } \\
\text { Lembur }\end{array}$ & $\begin{array}{c}\text { Kerja/Bulan } \\
\text { (Minngu) }\end{array}$ & $\begin{array}{c}\text { Jumlah } \\
\text { Jam } \\
\text { kerja/Bulan }\end{array}$ & $\begin{array}{c}\text { Gaji/Bulan } \\
\text { (Rp) }\end{array}$ & $\begin{array}{c}\text { Gaji/Jam } \\
\text { OOrang } \\
\text { (Rp) }\end{array}$ \\
\hline 8 & 6 & 3 & 4 & 204 & 3.500 .000 & 17.157 \\
\hline
\end{tabular}

Model perhitungan untuk mencari upah tenaga kerja yaitu :

$$
\begin{aligned}
\text { Gaji Kariawan Perjam } & =\frac{\text { Gaji } 1 \text { Bulan } / \text { Kariawan }}{\text { Jam Kerja } 1 \text { Bulan }} \\
& =\frac{3.500 .000}{204} \\
& =17.157
\end{aligned}
$$

\section{Perhitungan Biaya Penggantian Pencegahan (Cost Of Preventive)}

Perhitungan untuk cost of preventive pada masing-masing komponen kritis dapat dilihat pada tabel berikut :

Perhitungan untuk Cost Of Preventive $(\mathrm{Cp})$ untuk masing-masing komponen kritis dengan persamaan sebagai berikut :

Biaya Cp meliputi:

Biaya Operator Menganggur $=$ Waktu Pencegahan Penggantian x Biaya Operator

Menganggur $\mathrm{Cp}=$ Biaya Pembelian Komponen /Kebutuhan + Biaya Teknisi + Biaya Pemasangan + Biaya Operator Menganggur. 
Tabel 6 .Perhitungan Biaya Penggantian Pencegahan (Cost Of Preventive)

\begin{tabular}{|c|c|c|c|c|}
\hline $\begin{array}{c}\text { Biaya Tenaga } \\
\text { Kerja(Rp/Jam) }\end{array}$ & $\begin{array}{c}\text { Biaya Kehilangan } \\
\text { Produksi (Rp/Jam) }\end{array}$ & $\begin{array}{c}\text { Waktu Pergantian } \\
\text { Komponen (Jam) }\end{array}$ & $\begin{array}{c}\text { Harga } \\
\text { Komponen/Unit(Rp) }\end{array}$ & $\begin{array}{c}\text { Cost Of Preventif } \\
\text { (CP) Rp }\end{array}$ \\
\hline 34.314 & 4.500 .000 & 5 & 400.000 & 23.071 .570 \\
\hline 34.314 & 4.500 .000 & 4 & 1.500 .000 & 19.637 .256 \\
\hline 34.314 & 4.500 .000 & 6 & 400.000 & 27.605 .884 \\
\hline 34.314 & 4.500 .000 & 3 & 840.000 & 14.442 .942 \\
\hline
\end{tabular}

\section{Perhitungan Biaya Pergantian Secara Preventive Modularity Maintenance}

Setelah semua perhitungan dilakukan untuk mendapatkan selang waktu penggantian komponen yang optimal, maka langkah selanjutnya adalah menghitung total cost perawatan yang dapat dilihat pada tabel berikut :

Tabel 7. Perhitungan Biaya Pergantian Secara Preventive Modularity Maintenance

\begin{tabular}{|c|c|c|c|c|c|c|c|}
\hline Mesin & $\begin{array}{c}\text { Komponen } \\
\text { Kritis }\end{array}$ & $\begin{array}{l}\text { Frekluensi } \\
\text { Kerusakan }\end{array}$ & $\begin{array}{c}\text { Biaya Tenagaa } \\
\text { Kerja (Rp/Jam) }\end{array}$ & $\begin{array}{l}\text { Biaya Kehilangan } \\
\text { Produksi } \\
\text { (RpJJam) } \\
\end{array}$ & $\begin{array}{l}\text { Waktu Pergantian } \\
\text { Preventive (Jam) }\end{array}$ & $\begin{array}{c}\text { Harga } \\
\text { Komponen/linit } \\
\text { (Rp) }\end{array}$ & $\begin{array}{c}\text { Cost Of Preventif } \\
\text { Modulunity (CPMI) } \\
\mathbb{R p}\end{array}$ \\
\hline \multirow{4}{*}{$\begin{array}{l}\text { Ripple } \\
\text { Mill }\end{array}$} & Spacer Ring & 5 & 34.314 & 4.500 .000 & 0,044 & 400.000 & 2.199 .510 \\
\hline & Ripple Plate & 6 & 34.314 & 4.500 .000 & 0,089 & 1.500 .000 & 9.403 .554 \\
\hline & Ripple Side & 5 & 34,314 & 4.500 .000 & 0,044 & 400.000 & 2.199 .510 \\
\hline & V. Belt & 7 & 34.314 & 4.500 .000 & 0,153 & 840.000 & 6.573 .750 \\
\hline
\end{tabular}

Dengan model perhitungan sebagai berikut : CPM = Biaya Tenaga Kerja + Biaya Rehilangan Produksi X Waktu Preventive + Harga Komponen X Modul

$$
\begin{aligned}
& =34.314+4.500 .000 \times 0,040+400.000 \times 5 \\
& =2.199 .510
\end{aligned}
$$

Perbandingan Biaya Corrective (CF), Preventive (CP) dan Preventive Modularity Maintenance

Hasil perbandingan dari setiap perhitungan yang telah dilakukan dapat dilihat pada tabel berikut :

Tabel 8. Perbandingan Biaya Corrective (CF), Preventive (CP) dan Preventive Modularity Maintenance

\begin{tabular}{|c|l|c|c|c|}
\hline \multirow{2}{*}{ Mesin } & Komponen & $\begin{array}{c}\text { Cost Of Failure } \\
\text { (CF) Rp }\end{array}$ & $\begin{array}{c}\text { Cost Of Preventif } \\
\text { (CP) Rp }\end{array}$ & $\begin{array}{c}\text { Cost Of Preventif } \\
\text { Modularity (CPM) } \\
\text { Rp }\end{array}$ \\
\hline \multirow{4}{*}{$\begin{array}{c}\text { Ripple } \\
\text { Mill }\end{array}$} & Spacer Ring & 9.468 .628 & 23.071 .570 & 2.199 .510 \\
\cline { 2 - 5 } & Ripple Plate & 6.034 .314 & 19.637 .256 & 9.403 .554 \\
\cline { 2 - 5 } & Ripple Side & 14.00 .942 & 27.605 .884 & 2.199 .510 \\
\cline { 2 - 5 } & V- Belt & 5.374 .314 & 14.442 .942 & 6.573 .750 \\
\hline \multicolumn{2}{|c|}{ Total } & $\mathbf{3 4 . 8 8 0 . 1 9 8}$ & $\mathbf{8 4 . 7 5 7 . 6 5 2}$ & $\mathbf{2 0 . 3 7 6 . 3 2 4}$ \\
\hline
\end{tabular}

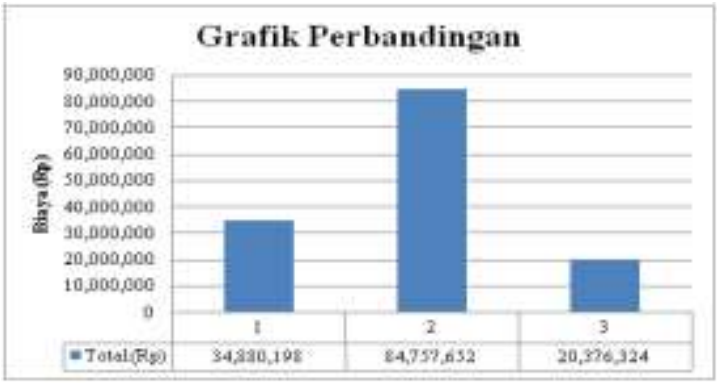

Gambar 1. Perbandingan Biaya CF, CP, CPM

(Sumber : Pengolahan Data, 2019)

Dapat dilihat bahwa penggantian preventive dengan modularity menghasilkan total cost yang paling kecil dibandingkan dengan yang lain, berdasarkan perhitungan yang telah dilakukan sebelumnya. Maka metode ini dapat digunakan untuk meminimasi biaya penggantian tiap komponen pada mesin ripple mill.

\section{KESIMPULAN}

Tipe distribusi frekuensi breakdown dari mesin ripple mill, mengikuti distribusi frekuensi breakdown case 2, dimana waktu terjadinya breakdown sulit untuk diprediksi.

Usulan kebijakan untuk perawatan mesin ripple mill adalah kebijakan penggantian preventive dengan modularity menghasilkan total cost yang paling kecil dibandingkan dengan yang lain, berdasarkan perhitungan yang telah dilakukan sebelumnya. Maka metode ini dapat digunakan untuk meminimasi biaya perawatan penggantian tiap komponen pada mesin ripple mill.

\section{DAFTAR PUSTAKA}

Ating Sudradjat. Pedoman Praktis Manajemen Perawatan Mesin Industri. Bandung, PT. Refika Aditama. 2011.

Blanchar, dan Prabowo, H.G. . Sistem Perawatan Mesin Press. Teknik Industri, Universitas Marcu Buana, Jakarta. Jurnal Pasti Industrial Emgineering Indiana John, 3(1), 3343. 2010. 
Daryanto. Keselamatan Kerja Peralatan Bengkel dan Perawatan Mesin. Bandung, CV Alfabeta.2010.

Ekawati, C. dan Mustofa, F. H. Jadwal Perawatan Preventive Pada Mesin Dyeing Menggunakan Metode Age Replacement Di Pt . Nobel Industries *. Jurnal Online Institut Teknologi Nasional, 4(2), 137-148. 2016.

Fajar Kurniawan. Teknik Dan Aplikasi Manajemen Perawatan Industri, Yogyakarta, Graha Ilmu. 2013.

Fakultas, D. et al. 'Preventive Maintenance System Dengan Modularity Design Sebagai Solusi Penurunan Biaya Maintainance (Studi Kasus di Perusahaan Tepung Ikan)', Jurnal Teknik Industri, 7(1), pp. 61-75. doi: 10.9744/jti.7.1.pp.6175. 2005.

Hery Suliantoro, dan Mustofa Muthi Said Susilo. Analisis Kebijakan Corrective dan Preventive Maintenance Pada Mesin Rapier Di PT. Tiga Manunggal Synthetic Indutries. Jurnal Ilmiah Teknik Industri, 1404. 2013.

Hariyanto, H., Rahayuningsih, S. and Santoso, H. 'Analisa Preventive Maintenance System Dengan Modularity Design Pada PT. Surya Pamenang', JATI UNIK: Jurnal Ilmiah Teknik dan Manajemen Industri, 1(1), p. 24 doi: 10.30737/jatiunik.v1i1.66. 2017.

Jaka Purnama, Yosua Anggara Putra, M. K 'Metode Age Replacement Digunakan Untuk Menentukan Interval Waktu Perawatan Mesin Pada Armada Bus', Seminar Nasional Sains dan Teknologi Terapan III 2015 Institut Teknologi Adhi Tama Surabaya ISBN, pp. 115-126. 2015.

Witonohadi, A., Amran, T. G. and
Herawati, N. 'Usulan Perawatan Mesin Secara Preventif Dengan Pendekatan Modularisasi Desain Pada Pt. Bai', Jurnal Teknik Industri, 3(1), pp. 1-9. doi: 10.25105/jti.v3i1.1581. 2013. 